\title{
Bronquiolitis obliterante con neumonía organizada y enfermedad de Crohn
}

\author{
P. Gil-Simón, J. Barrio Andrés, R. Atienza Sánchez, L. Julián Gómez, C. López Represa y A. Caro-Patón \\ Servicio de Aparato Digestivo. Hospital Río Hortega. Valladolid
}

\section{RESUMEN}

Las manifestaciones extraintestinales respiratorias en la enfermedad inflamatoria intestinal (EII) son excepcionales. Presentamos un caso de bronquiolitis obliterante con neumonía organizada $(\mathrm{BONO})$ en paciente con enfermedad de Crohn, en remisión clínica sin tratamientos farmacológicos.

Palabras clave: Bronquiolitis obliterante con neumonía organizada. Enfermedad de Crohn. Manifestaciones extraintestinales. Enfermedad inflamatoria intestinal.

\begin{abstract}
Extraintestinal respiratory manifestations in inflammatory bowel disease (IBD) are rare. We present a case of bronchiolitis obliterans organizing pneumonia (BOOP) in a patient with Crohn's disease, with clinical remission with no drug therapy.
\end{abstract}

Key words: Bronchiolitis obliterans organizing pneumonia. Crohn's disease. Extraintestinal manifestations. Inflammatory bowel disease. neumonía organizada y enfermedad de Crohn. Rev Esp Enferm Dig 2008; 100: 175-177.

\section{INTRODUCCIÓN}

Las manifestaciones extraintestinales de la enfermedad inflamatoria intestinal (EII) han sido descritas en casi todos los órganos de la economía. La incidencia varía entre el 21 y el $41 \%$ (1) y se ha comprobado que aumenta su frecuencia en relación con la duración de la enfermedad siendo más frecuentes en la enfermedad de Crohn (2-4).

Las manifestaciones pulmonares asociadas con la EII fueron descritas por primera vez en 1976 por Kraft y

Recibido: 06-09-07.

Aceptado: 17-10-07.

Correspondencia: Paula Gil Simón. Servicio de Aparato Digestivo. Hospital Río Hortega. Rondilla de Santa Teresa, 9. 47010 Valladolid. e-mail: pgpaula@hotmail.com cols. (5) en seis pacientes con supuraciones bronquiales crónicas. Desde entonces se han publicado diferentes casos con afecciones respiratorias, constituyendo la manifestación extraintestinal menos frecuente (6) y se asocian habitualmente más con la colitis ulcerosa (7), al contrario de lo que ocurre con el resto. Muchos casos presentan de forma concomitante otras manifestaciones extraintestinales (artritis, uveítis), lo que sugiere un mecanismo patogénico común (7), aunque por el momento es desconocido.

\section{CASO CLÍNICO}

Varón de 41 años sin hábitos tóxicos y con antecedente de intolerancia a la lactosa, diagnosticado en 2003 de enfermedad de Crohn con patrón inflamatorio y afectación 
ileal, que debutó dos años antes con un episodio de uveítis. Actualmente en remisión clínica sin ningún tratamiento de mantenimiento.

Presenta desde hace dos meses catarro de vías respiratorias altas, acompañado en los últimos días de tos, expectoración blanquecina y fiebre de $38^{\circ} \mathrm{C}$. Diagnosticado inicialmente de neumonía basal derecha, recibió tratamiento con antibióticos y mucolíticos con escasa mejoría. Posteriormente presentó disnea, expectoración purulenta, astenia y pérdida de $8-10 \mathrm{~kg}$. Tras no mejorar es remitido al hospital, ingresando en el servicio de neumología.

En la exploración física destaca palidez de piel, $\mathrm{T}^{\mathrm{a}}$ : $37,2{ }^{\circ} \mathrm{C}$ y en la auscultación pulmonar crepitantes en base derecha.

- Exploraciones complementarias:

- Sistemático: VSG: $66 \mathrm{~mm} \mathrm{1}$ 1a $^{\mathrm{a}}$ hora, leucocitos: 6.900/ul con fórmula normal, hematíes: 4.570.000/ul; $\mathrm{Hb}: 11,9$ g/dl; Hto: 35,6\%; plaquetas: 366.000/ul. Bioquímica: sin hallazgos significativos. Coagulación: normal. Sat $\mathrm{O}_{2}: 95 \%$.

- Hemocultivos negativos para anaerobios y aerobios. Serología VIH: negativa. Bacteriología de esputo negativa. Ag bacterianos en orina: negativo para neumococo y legionella.

- Rx de tórax al ingreso: infiltrados alveolares en base derecha y mínimos en base izquierda, que en controles radiológicos posteriores se hacen migratorios a segmento 6, afectando también a lóbulo medio derecho. Días más tarde se objetiva condensación en lóbulo superior derecho disminuyendo los infiltrados basales.

- Espirometría: FVC: 2,52 1 (56\%); FEV1: 2,23 1 (60\%); FEV1/VC: 78\%; MMEF25-75: 1,961 (46\%): insuficiencia ventilatoria no obstructiva.

- TAC torácico: consolidación parenquimatosa extensa en lóbulo superior derecho; consolidación en resolución y pérdida de volumen en lóbulo medio derecho; consolidación en resolución parcial en lóbulo inferior derecho con imagen de infiltrado alveolar e imagen en resolución parcial en segmento posterior de lóbulo superior izquierdo (Fig. 1).

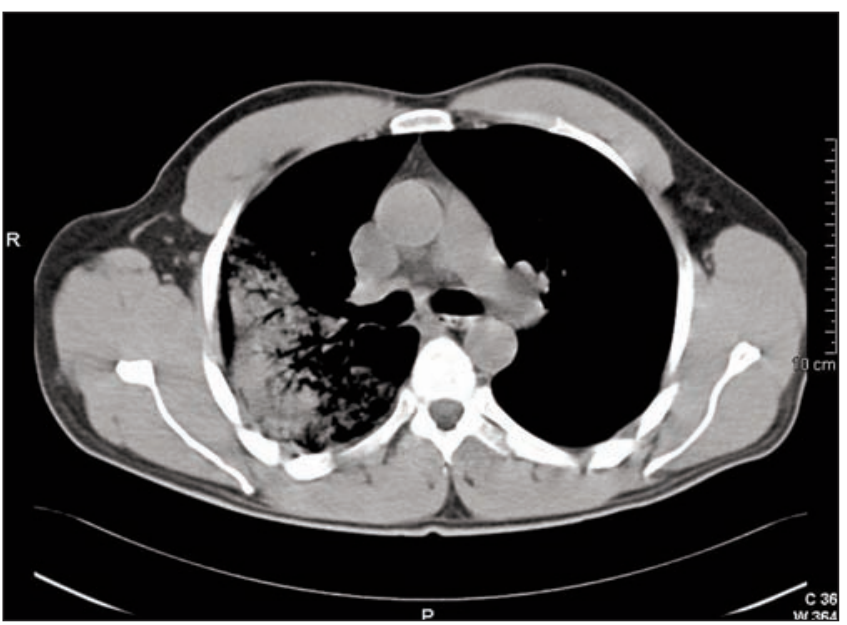

Fig. 1. Imágenes de consolidación parenquimatosa pulmonar en el TAC.
- Tras los resultados se realizó fibrobroncoscopia con lavado bronquioalveolar (BAL) y biopsia transbronquial (BTB): sin objetivarse lesiones endoluminales, ni alteración de la mucosa. Microbiología de BAL: flora normal de vías altas con cultivo de Legionella, Gram, BAAR y hongos negativo. BAL: 80 células $/ \mathrm{mm}^{3}, 65 \%$ macrófagos, 25\% linfocitos (aumentado), 5\% eosinófilos y 5\% PMN. Poblaciones linfocitarias: cociente CD4/CD8: 0,87. Biopsia transbronquial: septos interalveolares ensanchados por inflamación crónica y fibrosis. Hiperplasia de células alveolares con descamación de neumocitos a la luz y exudado granular PAS negativo. Tejido de granulación mixoide que emerge de bronquios terminales hacia la luz. No lesiones granulomatosas ni membranas hialinas. Todo lo anterior es compatible con neumonía organizada con bronquiolitis obliterante.

Se inició tratamiento con prednisona a dosis de 1 $\mathrm{mg} / \mathrm{kg} /$ día cediendo la fiebre y con mejoría del resto de la sintomatología. Al mes y a los tres meses el paciente se encuentra asintomático y los controles radiológicos son normales.

\section{DISCUSIÓN}

Las alteraciones respiratorias varían desde manifestaciones subclínicas hasta alteraciones de la vía aérea, enfermedades obstructivas e intersticiales, que en algunos casos pueden producir situaciones de extrema gravedad $(7,8)$ y en algunos casos pueden aparecer incluso años después del inicio de la enfermedad intestinal (9) (Tabla I).

Es importante conocer que las afecciones respiratorias pueden estar inducidas por los fármacos utilizados en el tratamiento de EII (sulfasalazina, mesalamina, infliximab y metotrexato) porque suele mejorar tras suspender el

Tabla I. Manifestaciones pulmonares en pacientes con enfermedad inflamatoria intestinal

Enfermedades de las vías aéreas superiores

Estenosis glótica y subglótica de laringe

Estenosis e inflamación de la tráquea

Bronquitis crónica simple

Distensión bronquial

Supuración crónica bronquial

Bronquiectasias

Enfermedades de las vías aéreas inferiores

Bronquiolitis necrotizante

Bronquiolitis granulomatosa

Bronquiolitis obliterante

Panbronquiolitis difusa

Enfermedades del parénquima pulmonar

Bronquiolitis obliterante con neumonía organizada

Infiltrados periféricos y eosinofilia

Enfermedad pulmonar intersticial

Neumonitis intersticial descamativa

Neumonitis intersticial inespecífica

Nódulos necrobióticos estériles 
medicamento y en algunos casos responden bien al tratamiento con esteroides (7).

Dentro de las enfermedades del parénquima pulmonar una de las enfermedades descritas es la bronquiolitis obliterante con neumonía organizada (BONO) que se suele manifestar con fiebre, malestar general, tos y dolor torácico en ocasiones (6). La BONO es una enfermedad pulmonar poco frecuente, caracterizada por la presencia de pólipos de tejido de granulación localizados de forma parcheada en el interior de los alveolos, los conductos alveolares y bronquiolos, asociada a su vez a una neumonía organizada focal (10). La tomografía axial computerizada de alta resolución (TACAR) es la prueba de elección para el diagnóstico de las enfermedades pulmonares intersticiales difusas y, aunque en la BONO no existen patrones radiológicos específicos, la TACAR ayuda a su diagnóstico. Los hallazgos radiológicos más frecuentes son las consolidaciones parenquimatosas y el patrón en vidrio deslustrado (10).

Camus y cols. (11) en 1993 publicaron una serie de 33 pacientes con EII y manifestaciones pulmonares, más del $80 \%$ de los cuales eran colitis ulcerosa. Describieron 6 pacientes que desarrollaron BONO, sólo uno de ellos con enfermedad de Crohn. Los síntomas más comunes fueron la fiebre, disnea, tos y dolor torácico. En uno de ellos observaron además historia de infección de vías respiratorias altas, como en nuestro paciente. Todos tenían broncoscopia normal y el diagnóstico se hizo tras el estudio anatomopatológico de tejido pulmonar.

Diez años más tarde, en 2003, Storch y cols. (7) realizaron una revisión de más de 400 casos publicados en la literatura de pacientes con EII y manifestaciones pulmonares, de los que 150 tuvieron enfermedad pulmonar activa y el resto manifestaciones subclínicas. Describieron los diferentes patrones de enfermedad pulmonar. Estudiaron tanto los patrones relacionados con la propia enfermedad como los inducidos por los fármacos utilizados para el tratamiento de EII. De los 400 casos analizados, encontraron 9 casos con BONO, 8 de los cuales con colitis ulcerosa, con una edad media de presentación de 27 años. Los síntomas más comunes de presentación de la enfermedad fueron la disnea y la tos, el diagnóstico se realizó mediante la biopsia transbronquial y todos res- pondieron bien el tratamiento con esteroides, al igual que en nuestro caso.

La BONO es una de las afecciones respiratorias intersticiales que pueden aparecer en los pacientes con EII. En nuestro caso, sin tratamientos farmacológicos de mantenimiento, podemos considerarla como una manifestación extraintestinal, con curso evolutivo independiente de la actividad intestinal, que presentó una buena respuesta al tratamiento con corticoides.

Creemos que es importante tener presente las manifestaciones pulmonares, tanto las secundarias a los tratamientos farmacológicos (5-ASA, infliximab o metotrexato) como las asociadas a la propia enfermedad para realizar un diagnóstico y tratamiento precoz.

\section{BIBLIOGRAFÍA}

1. Rankin GB, Watts HD, Melnyk CK, et al. National Cooperative Crohn's Disease Study: Extra-intestinal manifestations and perianal complications. Gastroenterol 1979; 77: 914-20.

2. Veloso F, Carvalho J, Magro F. Inmune-related manifestations of inflammatory bowel disease: A study of 792 patients. J Clin Gastroenterol 1996; 23: 29-34.

3. Repiso A, Alcántara M, Muñoz-Rosas C, Rodríguez-Merlo R, PérezGrueso MJ, Carrobles JM, et al. Extraintestinal manifestations of Crohn's disease: Prevalence and related factors. Rev Esp Enferm Dig 2006; 98: 510-7.

4. Pajares JM, Gisbert JP. Epidemiología de la enfermedad inflamatoria intestinal en España. Una revisión sistemática. Rev Esp Enferm Dig 2001; 93: 9-20.

5. Kraft SC, Earle RH, Roesler M, Esterly JR. Unexplained bronchopulmonary disease with inflammatory bowel disease. Arch Intern Med 1976; 136: 454-9.

6. Vennera MC, Picado C. Manifestaciones pulmonares de las enfermedades inflamatorias intestinales. Arch Bronconeumol 2005; 41: 93-8.

7. Storch I, Sachar D, Katz S. Pulmonary manifestations of inflammatory bowel disease. Inflamm Bowel Dis 2003; 9: 104-15.

8. Camus PH, Colby TV. The lung in inflammatory bowel disease. Eur Respir J 2000; 15: 5-10.

9. Mahadeva R, Walsh G, Flower CDR, Shneerson JM. Clinical and radiological characteristics of lung disease in inflammatory bowel disease. Eur Respir J 2000; 15: 41-8.

10. Bravo A, Torres MI, García F, Sánchez C, Parrón M, Pardo M. Patrones de presentación de la neumonía organizada mediante tomografía computarizada de alta resolución. Arch Bronconeumol 2006; 42: 413-6.

11. Camus P, Piard F, Ashcroft T, Gal AA, Colby TV. The lung in inflammatory bowel disease. Medicine (Baltimore) 1993; 72: 151-83. 